\title{
Role of osteopontin in the regulation of human bladder cancer proliferation and migration in $\mathrm{T} 24$ cells
}

\author{
SONG-TAO XU ${ }^{1 *}$, CHUN GUO $^{1 *}$, XIANG DING $^{2 *}$, WEN-JUAN FAN ${ }^{1}$, \\ FU-HUA ZHANG ${ }^{1}$, WAN-LING XU ${ }^{1}$ and YONG-CHAO MA ${ }^{1}$ \\ ${ }^{1}$ Department of Clinical Medicine, Luohe Medical College, Luohe, Henan 462002; ${ }^{2}$ Department of Urology, \\ The First Affiliated Hospital of Soochow University, Suzhou, Jiangsu 215006, P.R. China
}

Received February 19, 2014; Accepted November 19, 2014

DOI: $10.3892 / \mathrm{mmr} .2015 .3202$

\begin{abstract}
Osteopontin (OPN), a secreted acid glycoprotein with a variety of functions, promotes tumor proliferation, differentiation, invasion and metastasis. The aim of the current study was to investigate whether OPN may serve as a potential therapeutic target for human bladder cancer. RNA interference (RNAi) was performed to downregulate the expression of the OPN gene in T24 human bladder cancer cells. The mRNA and protein expression levels of OPN following RNAi were determined using reverse transcription-quantitative polymerase chain reaction and western blot analysis, respectively. In addition, the cell cycle progression, apoptosis and proliferation were investigated using by flow cytometric analysis and MTT assay. The cell invasion ability was measured using a Matrigel transwell assay. The mRNA and protein expression levels of OPN were found to be significantly downregulated following RNAi. The proliferation and invasion of T24 cells were significantly inhibited in vitro. In conclusion, RNAi-targeting OPN may inhibit the proliferation, invasion and tumorigenicity of human bladder cancer cells. Therefore, OPN may serve as a potential therapeutic target for human bladder cancer.
\end{abstract}

\section{Introduction}

Bladder cancer is a common malignant tumors of the urinary system. In 2005, 63,210 new cases of bladder cancer were identified in America, of which 13,180 succumbed to the disease (1). With the development of an aging population, bladder cancer incidence is increasing year after year as incidence increases with age. Surgery is the main treatment method for bladder cancer; however, the 5-year average survival period remains

Correspondence to: Dr Yong-Chao Ma, Department of Clinical Medicine, Luohe Medical College, 148 Daxue Road, Luohe, Henan 462002, P.R. China

E-mail: 13839527381@163.com

*Contributed equally

Key words: osteopontin, bladder cancer, RNA interference poor (2). A previous study has demonstrated that the most important prognostic factors of bladder cancer include the pathological grading and staging (3). Long-term survival may be achieved through early detection and treatment. With the elucidation of the molecular biology of bladder cancer, gene therapy represents a novel method for the adjuvant treatment of the disease. Osteopontin (OPN) is a secreted acid glycoprotein with a variety of functions. OPN was initially isolated from the bone matrix and subsequently found in the tissues or cells of the placenta, decidua, smooth muscle and macrophages, as well as in various body fluids. In addition, OPN is an important component of the extracellular matrix. Previous studies have demonstrated that OPN is expressed in various tumor tissues and promotes tumor proliferation, differentiation, invasion and metastasis (4-9). A number of studies have shown that shorter survival time and poor prognosis are associated with high levels of OPN (10-13), while low plasma levels of OPN in patients are associated with good prognosis $(14,15)$.

RNA interference (RNAi) is a process of typical post-transcriptional regulation of gene expression, which is a conservative behavior in biological evolution, with resistance to virus invasion and maintaining the role of genetic stability $(16,17,18)$. RNAi is induced by double-stranded RNA (dsRNA) gene silencing (18). When dsRNA is transported into cells, mRNA degrades due to the homologous sequences of dsRNA, thereby inhibiting the expression of the gene and resulting in the silencing of the gene expression $(18,19)$. In the present study, RNAi was used to reduce the expression of OPN in T24 human bladder carcinoma cells in order to investigate the effect of OPN expression on the biological behavior of T24 cells.

\section{Materials and methods}

Reagents. $\alpha$-Minimum essential medium ( $\alpha$-MEM), fetal bovine serum (FBS), penicillin/streptomycin and TRIzol ${ }^{\circledR}$ reagent were purchased from Gibco Life Technologies (Rockville, MD, USA). Rabbit anti-human monoclonal antibodies against total caspase-3, caspase-8, caspase-9 and p53 $(1: 1,000)$ were purchased from Cell Signaling Technology, Inc. (Beverly, MA, USA), while rabbit anti-human monoclonal antibodies against OPN and $\beta$-actin $(1: 1,000)$ were purchased from Santa Cruz Biotechnology, Inc. (Dallas, TX, USA). All 
other chemicals and reagents used in the present study were of analytical grade.

Cell culture. The T24 human bladder cancer cell line was obtained from the American Type Culture Collection (Manassas, VA, USA) and cultured in $\alpha$-MEM supplemented with $10 \%(\mathrm{v} / \mathrm{v}) \mathrm{FBS}$ and $1 \%(\mathrm{v} / \mathrm{v})$ penicillin-streptomycin solution and incubated at $37^{\circ} \mathrm{C}$ in $5 \% \mathrm{CO}_{2}$ humidified air. The culture medium was refreshed every three days.

Small interfering (siRNA) for OPN. Four siRNA sequences targeting human OPN and a negative control siRNA were obtained from Shanghai GeneChem Co, Ltd (Shanghai, China). The siRNA sequences were designed using software (OCK-iT ${ }^{\mathrm{TM}}$ RNAi Designer) from Life Technologies (Carlsbad, CA, USA) by Shanghai GeneChem Co, Ltd. The siRNA sequences were as follows: pSC-1, 5'-GAC CATTCTGATGAATCTGAT-3'; pSC-2, 5'-GAGCATTCC GATGTGATTGAT-3'; pSC-3, 5'-GAGGAGTTGAATGGT GCATA-3'; pSC-4, 5'-CACAAGCAGTCCAGATTATA-3'). The OPN eukaryotic expression plasmid was constructed and co-transfected with 293T cells (American Type Culture Collection, Manassas, VA, USA). Based on the inhibition efficiency of the OPN gene, an effective RNAi sequence was identified: 5'-GAGCATTCCGATGTGATTGAT-3'. Next, the sequence of shRNA was designed as follows: Forward, 5'-CCGGGAGCATTCCGATGTGATTGATTTCAAGAG AATCAATCACATCGGAATGCTCTTTTTG-3', and reverse, 5'-AATTCAAAAAGAGCATTCCGATGTGAT TGATTCTCTTGAAATCAATCACATCGGAATGCTC-3'. shRNA was synthesized by Shanghai GeneChem Co., Ltd.

Lentivirus plasmid construction. A pGCSIL-green fluorescent protein (GFP) vector (Shanghai GeneChem Co., Ltd) was digested using AgeI and EcoRI (New England Biolabs (Beijing) Ltd., Beijing, China) in order to linearize it. The target gene and the digested linearized vector were directionally connected and the products were transformed into bacterial competent cells. Next, polymerase chain reaction (PCR) identification of positive clones was performed by sequencing and comparative analysis. Viral vectors containing the various RNAi sequences were used to transfect 293T cells using Lipofectamine ${ }^{\circledR} 2000$ (Invitrogen Life Technologies, Carlsbad, CA, USA), according to the manufacturer's instructions. Following transfection for $24 \mathrm{~h}$, the cells were observed by fluorescence microscopy using an Olympus Micropublisher 3.3 RTV (Olympus Corp., Tokyo, Japan). After $48 \mathrm{~h}$ of transfection, western blot assay was performed to analyze the target protein expression, which determined the interference effects of various targets. Finally, the correct siRNA sequence (pSC-2) for the OPN gene and RNAi expression vector were constructed.

Cell transfection. The T24 cells were divided into six-well plates $\left(5 \times 10^{4}\right.$ cells/well) one day prior to the virus infection and cultured at $37^{\circ} \mathrm{C}$ in $5 \% \mathrm{CO}_{2}$ humidified air. On the first day of infection, experiments were performed on plasmids containing RNAi lentiviral particles according to the experimental design. Briefly, when cell confluence reached $30 \%$, the culture medium was refreshed. The three lentiviruses were added according to multiplicity of infection (MOI), ten. The three transfection groups were as follows: Empty plasmid group, transfected with an empty lentiviral vector without any sequence; negative control group, transfected with a lentiviral vector containing a negative control RNAi sequence (5'-TTATCGACGTATTGGTAGACG-3'); OPN RNAi group, transfected with a lentivirus containing OPN RNAi sequences. The cells were transfected for $12 \mathrm{~h}$, if there was no clear cytotoxic effect induced within this time-period, the incubation was continued for a further $24 \mathrm{~h}$ under identical conditions prior to refreshment of the medium. If there was a significant cytotoxic effect following the initial $12 \mathrm{~h}$ incubation, the culture medium was refreshed immediately.

Reverse transcription-quantitative PCR (RT-qPCR) assay for OPN $m R N A$. The infection efficiency of OPN-RNAi was detected by RT-qPCR. After transfection for five days, the cells were collected and total RNA was isolated using the TRIzol ${ }^{\circledR}$ reagent (Invitrogen Life Technologies) and quantified by spectrophotometry (Eppendorf Biospectrometer Basic; Eppendorf, Hamburg, Germany). Following isolation, $2 \mu \mathrm{g}$ total RNA from each sample was reverse transcribed using the HiFi-MMLV cDNA Kit (Beijing CoWin Biotech Co., Ltd, Beijing, China) according to the manufacturer's instructions. The primer sequences of OPN and GAPDH (Generay Biotech Co. Ltd, Shanghai, China) and the annealing temperatures used in this study are presented in Table I. RT-qPCR was performed using a SYBR ${ }^{\circledR}$ Premix Ex Taq ${ }^{\mathrm{TM}}$ kit (Takara Biotechnology Co., Ltd., Dalian, China), according to the manufacturer's instructions. All RT-qPCR reactions were performed on an ABI PRISM 7700 sequence detection system (Applied Biosystems Life Technologies, Grand Island, NY, USA). In each reaction, $1 \mu \mathrm{l}$ cDNA, $10 \mu 1 \mathrm{SYBR}^{\circledR}$ Premix Ex Taq ${ }^{\mathrm{TM}}$ and $0.4 \mu \mathrm{M}$ forward and reverse primers in a total volume of $20 \mu \mathrm{l}$ were used. The reaction conditions were set as follows: one cycle at $95^{\circ} \mathrm{C}$ for $15 \mathrm{sec}$, followed by 25 cycles at $95^{\circ} \mathrm{C}$ for $5 \mathrm{sec}$ and $60^{\circ} \mathrm{C}$ for $30 \mathrm{sec}$. RT-qPCR was performed in triplicate for each sample. GAPDH was used as an internal control, and all the results were analyzed using the standard $2^{-\Delta \Delta C T}$ method, as described previously (20).

Western blot assay. Total protein of the collected cells was extracted six days post-infection. At the end of the treatment, the cell culture medium was aspirated and the cells were detached in PBS by scraping. The detached cells were centrifuged at $21,000 \mathrm{x} \mathrm{g}$ at $4^{\circ} \mathrm{C}$ for $15 \mathrm{~min}$ and the cell pellets were then lysed in $300 \mu 1$ radioimmunoprecipitation lysis buffer (Cytobuster protein extraction reagent; P0013; Beyotime Institure of Biotechnology, Shanghai, China) with $25 \mathrm{mM} \mathrm{NaF}, 1 \mathrm{mM} \mathrm{Na} \mathrm{VO}_{4}$, and $1 \mathrm{X}$ protease inhibitor cocktail [Aprotinin $(2 \mu \mathrm{g} / \mathrm{ml})$, Leupeptin $(10 \mu \mathrm{g} /$ $\mathrm{ml})$, Pepstain A $(1 \mu \mathrm{g} / \mathrm{ml}), \operatorname{PMSF}(1 \mathrm{mM})$, EDTA $(5 \mathrm{mM})$, EGTA $(1 \mathrm{mM})$, Na Fluoride $(10 \mathrm{mM})$, Na Orthovanadate (1 mM); Roche Diagnostics, Basel, Switzerland] dissolved in distilled water. Protein concentrations were quantified by spectrophotometry (Eppendorf BioSpectrometer; Eppendorf, Hamburg, Germany). For western blot analysis, equal amounts of protein $(50 \mu \mathrm{l})$ from each sample were subjected to SDS-PAGE and electrotransferred onto polyvinylidine fluoride (PVDF) membranes (EMD Millipore, Bedford, MA, USA). The membranes were blocked with $5 \%(\mathrm{w} / \mathrm{v})$ bovine 
Table I. Sequences of primers used for reverse transcription-quantitative polymerase chain reaction.

\begin{tabular}{llccc}
\hline Gene & \multicolumn{1}{c}{$\begin{array}{c}\text { Primer sequences } \\
\text { (forward/reverse) }\end{array}$} & $\begin{array}{c}\text { GenBank } \\
\text { number }\end{array}$ & $\begin{array}{c}\text { Annealing } \\
\text { temperature }\left({ }^{\circ} \mathrm{C} \text { ) }\right.\end{array}$ & $\begin{array}{c}\text { Product length } \\
\text { (bp) }\end{array}$ \\
\hline Osteopontin & 5'-GTTGGTGGAGGATGTCTG-3'/ & NM_000582 & 62 & 344 \\
\multirow{3}{*}{ GAPDH } & 5'-TACTTGGAAGGGTCTGTG-3' & & & 208 \\
& 5'-AACGGATTTGGTCGTATTG-3'/ & NM_002046 & 62 & \\
\hline
\end{tabular}

serum albumin (Gibco Life Technologies) in Tris-buffered saline/Tween 20 [10 mM Tris, $150 \mathrm{mM} \mathrm{NaCl}$, and $0.1 \%(\mathrm{v} / \mathrm{v})$ Tween 20; $\mathrm{pH} 7.5$ ] for $1 \mathrm{~h}$ at room temperature and incubated with primary antibodies overnight at $4^{\circ} \mathrm{C}$. Incubation with goat monoclonal anti-rabbit secondary antibody was performed at room temperature for $1 \mathrm{~h}$ (1:8,000; Santa Cruz Biotechnology, Inc.). An enhanced chemiluminescence system (Beyotime Institute of Biotechnology) was used to detect immunoreactive protein signals. The protein signals were then exposed to $\mathrm{X}$-ray films for visualization and photographed (Canon IXUS 105; Canon Zhuhai, Inc., Zhuhai, China) and quantified using Image J software version 1.38 (National Institutes of Health, Bethesda, MA, USA). For re-probing, PVDF membranes were stripped with $0.2 \mathrm{M} \mathrm{NaOH}$ for 10 min before blocking with an additional primary antibody. The expression levels of the molecules of interest were determined relative to $\beta$-actin and each experiment was repeated three times.

MTT assay for the proliferation of T24 cells. When the T24 cell confluence reached $30 \%$, the medium was refreshed and lentiviral transfection of the three groups was performed according to the aforementioned protocol. After 12, 24, 48, 72 or 96 h, MTT $(20 \mathrm{mg} / \mathrm{ml}$; Amresco LLC, Solon, OH, USA) was added and incubated for $4 \mathrm{~h}$, followed by addition of $150 \mu \mathrm{l}$ dimethyl sulfoxide (Sigma-Aldrich, St. Louis, MO, USA). After shaking for $10 \mathrm{~min}$, the absorbance was measured at $570 \mathrm{~nm}$ using a microplate reader (Thermo Multiskan MK3; Thermoelectric Electronics Co., Ltd, Shanghai, China).

Flow cytometric analysis for determination of cell cycle progression and apoptosis. Flow cytometric analysis (FACS Calibur; BD Biosciences, Franklin Lakes, NJ, USA) was used to detect the cell cycle progression and apoptosis. The cells were stained with propidium iodide (PI; KGI Biotechnology Development Co. Ltd., Nanjing, China), followed by detection of the cell cycle progression. The cell suspension was prepared and the degree of apoptosis was detected using an Annexin V-APC kit (Promega, Madison, WI, USA). Briefly, cells were scraped, washed twice with PBS and centrifuged. Cells were incubated in $1 \mathrm{X}$ binding buffer containing Annexin V-APC and PI in dark for $15 \mathrm{~min}$. Apoptotic cells were examined using flow cytometry. Each sample was analyzed in triplicate.

Matrigel Transwell assay for cell invasion. Matrigel invasion chambers (Promega) were hydrated for $4 \mathrm{~h}$ prior to the initiation of the invasion assay. After transfection for $\sim 72 \mathrm{~h}$, log-phase cells $\left(4 \times 10^{4} / \mathrm{ml}\right)$ cultured in $\alpha$-MEM without FBS were seeded in the upper chamber of the wells, while the lower chambers were filled with $500 \mu \mathrm{l}$ complete $\alpha$-MEM supplemented with $10 \%$ FBS. The cells were allowed to migrate for $10 \mathrm{~h}$, followed by the invasion assay. Three fields in the central and surrounding parts of each membrane were randomly selected for counting. The experiments were performed in triplicate and the data were compared with the negative control group.

Enzyme-linked immunosorbent assay (ELISA). After transfection for $\sim 72 \mathrm{~h}$, the T24 cells were collected for ELISA. The concentrations of matrix metalloproteinase (MMP)-9 and MMP-2 in the cell culture supernatants were quantified using MMP-9 and MMP-2 ELISA kits (R\&D Systems, Minneapolis, MN, USA). Each assay was performed five times.

Statistical analysis. SAS 9.0 software (SAS Institute, Inc., Cary, NC, USA) was used for statistical analysis. Western blots were quantified by measuring the relative density of protein bands recognized by a particular antibody using the Image $\mathbf{J}$ software. The results are expressed as the mean \pm standard deviation. Statistical analysis was conducted with Student's $t$-test for comparison of two groups and $\mathrm{P}<0.05$ was considered to indicate a statistically significant difference.

\section{Results}

Expression of OPN is clearly inhibited by RNAi. T24 cells were cultured in vitro for $24 \mathrm{~h}$. The positive expression rate of GFP was detected by fluorescence microscopy $48 \mathrm{~h}$ after lentiviral infection of T24 cells. The results indicated that the infection efficiency was $>90 \%$. The relative mRNA expression levels of OPN were detected by RT-qPCR 5 days after lentiviral infection of T24 cells. The relative protein expression levels of OPN were detected using western blot analysis 6 days subsequent to lentiviral transfection of T24 cells. The results revealed that the OPN expression level in the interference group was significantly lower compared with the negative control and empty plasmid groups $(\mathrm{P}<0.05$; Fig. 1$)$.

Effect of OPN-RNAi on the growth of T24 cells. The results of the MTT assay demonstrated that the growth rate of cell proliferation was gradually reduced in the interference group over $96 \mathrm{~h}$. Cell proliferation was significantly reduced compared with the control groups after $48 \mathrm{~h}(\mathrm{P}<0.05$; Fig. 2C).

Cell cycle analysis by flow cytometry. The results of the cell cycle analysis revealed that a number cells were blocked in $G_{1}$ phase in the interference group (Fig. 2). A significant 
A

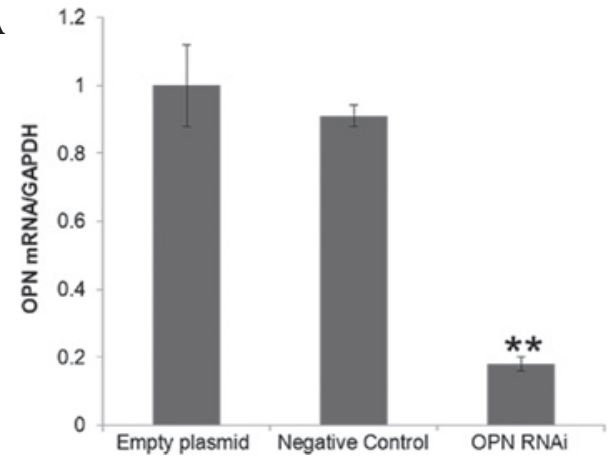

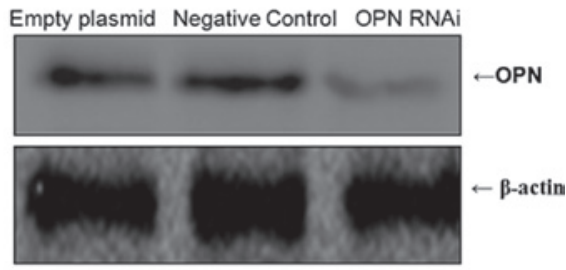

Figure 1. Effect of OPN RNAi on the expression of OPN in T24 cells. (A) Reverse transcription-quantitative polymerase chain reaction was used to detect the effect of OPN RNAi on the mRNA expression of OPN. (B) The protein expression of OPN in T24 cells was detected using western blot analysis. ${ }^{* *} \mathrm{P}<0.01$, vs. negative control group. OPN, osteopontin; RNAi, RNA interference.

A

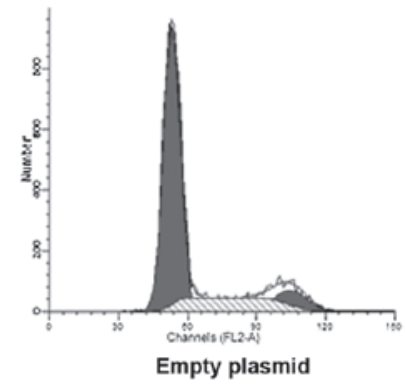

$\mathbf{B}$

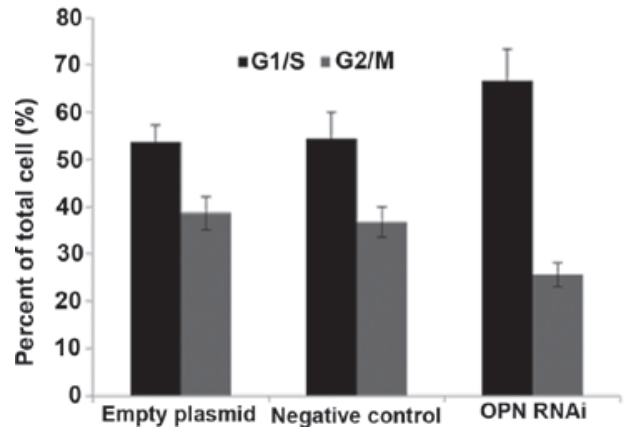

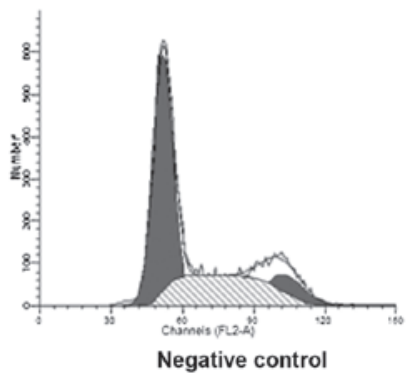

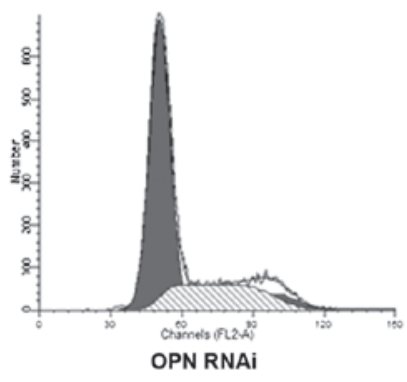

C

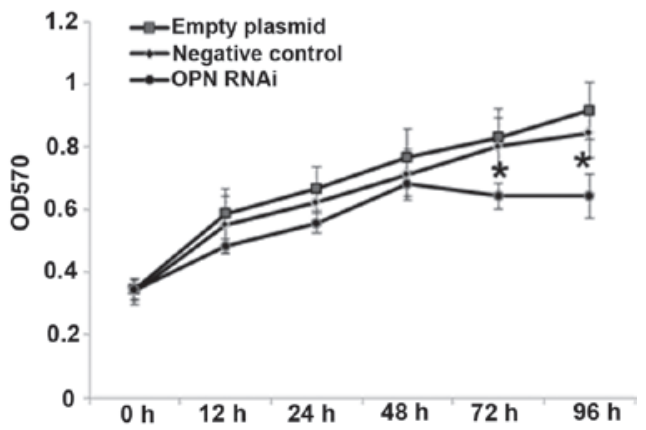

Figure 2. Effect of OPN RNAi on the regulation of T24 cell cycle and proliferation. (A) Cell cycle progression upon OPN RNAi treatment was analyzed using flow cytometry. The data are expressed as the mean \pm standard deviation from three separate experiments. (B) Quantification of cell cycle analysis. (C) Cell proliferation was monitored with MTT assay. ${ }^{*} \mathrm{P}<0.05$, vs. negative control group. OPN, osteopontin; RNAi, RNA interference.

difference was observed between the number of cells in the $\mathrm{G}_{1} / \mathrm{S}$ phase in the interference group compared with the negative control and empty plasmid groups $(\mathrm{P}<0.01)$. $\mathrm{G}_{2} / \mathrm{M}$-phase cells in the interference group were significantly less compared with those in the negative control and empty plasmid groups $(\mathrm{P}<0.05)$.

Effect of OPN-RNAi on the apoptosis of T24 cells. Cell apoptosis was found to be significantly increased in the interference group compared with the negative control and empty plasmid group $(\mathrm{P}<0.05)$. No significant differences were identified between the apoptosis rates of the negative control and empty plasmid groups $(\mathrm{P}>0.05)$, as shown in Fig. 3A. The expression levels of apoptosis proteins were detected by western blot analysis (Fig. 3B). The results indicated that the expression levels of caspase-3, caspase-8, caspase- 9 and p53 increased significantly upon OPN-RNAi treatment, when compared with the empty plasmid and negative control groups.
Impact of OPN-RNAi on invasion of T24 cells. The number of cells invading through the membrane in the interference group was significantly lower compared with the negative control and empty plasmid groups $(\mathrm{P}<0.05)$. The findings indicated a reduced capacity of tumor invasion in the interference group in T24 cells, as shown in Fig. 4.

Effect of OPN-RNAi on the expression levels of migration relate proteins. The concentrations of MMP-2 and MMP-9 were measured in the cell culture medium. As expected, OPN-RNAi treatment was found to significantly downregulate the expression of these proteins (Fig. 5).

\section{Discussion}

Osteopontin (OPN) is a secreted acidic glycoprotein with high expression in various tumor tissues $(10-13,21)$. Inhibition of the mRNA expression of OPN has been shown 
A

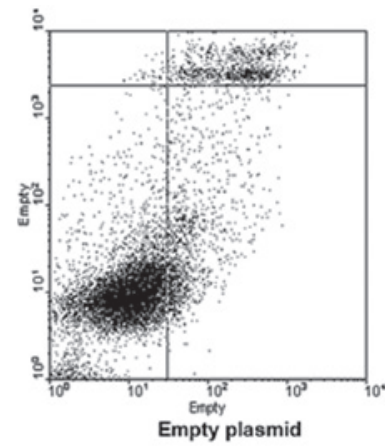

B

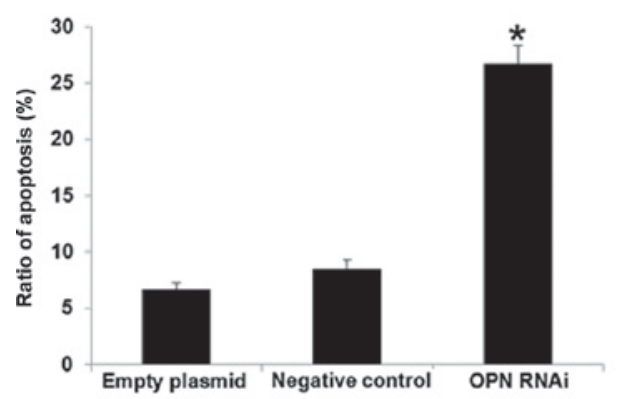

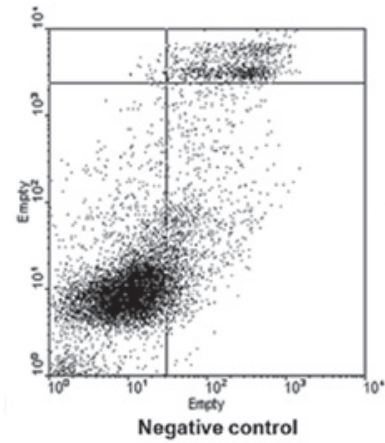

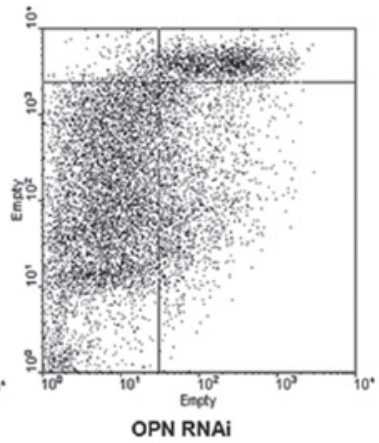

C Empty plasmid Negative control OPN RNAi

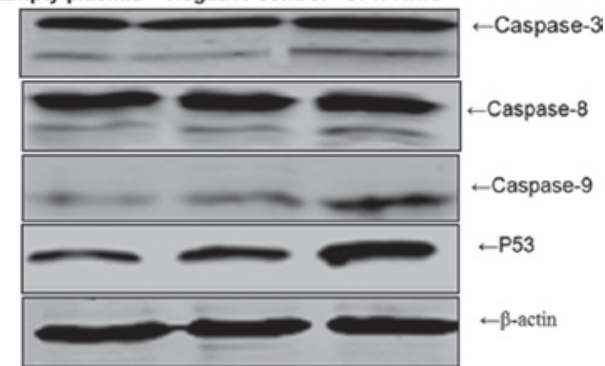

Figure 3. Effect of OPN RNAi on the apoptosis of T24 cells. (A) Following transfection for $72 \mathrm{~h}$, the apoptosis of T24 cells was detected by Annexin V-APC staining. Data are expressed as the mean \pm standard deviation from three separate experiments. (B) Quantification of Annexin V-APC staining. "P $<0.05$, vs. negative control group. (C) Apoptosis of proteins was detected by western blot analysis. OPN, osteopontin; RNAi, RNA interference; APC, allophycocyanin.

A

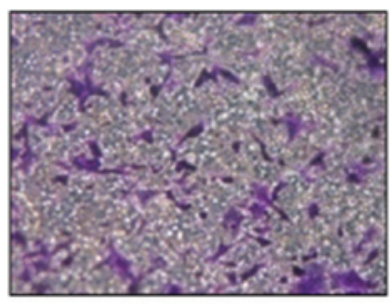

Empty plasmid

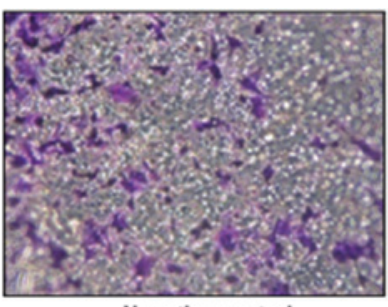

Negative control

B

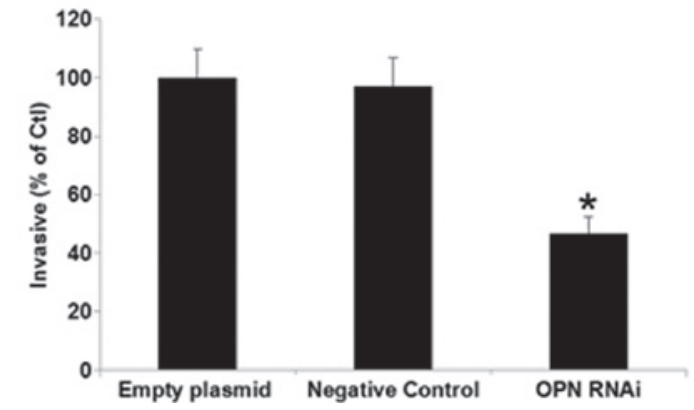

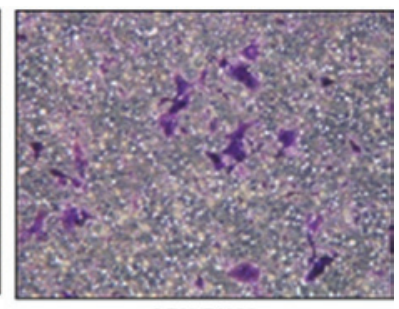

OPN RNAi

\section{calculated. "P<0.05, vs. negative control group. OPN, osteopontin; RNAi, RNA interference.}

Figure 4. Effect of OPN RNAi on the invasion of T24 cells. (A) Cell invasion ability was monitored with a Transwell assay, and the (B) invasion ratio was
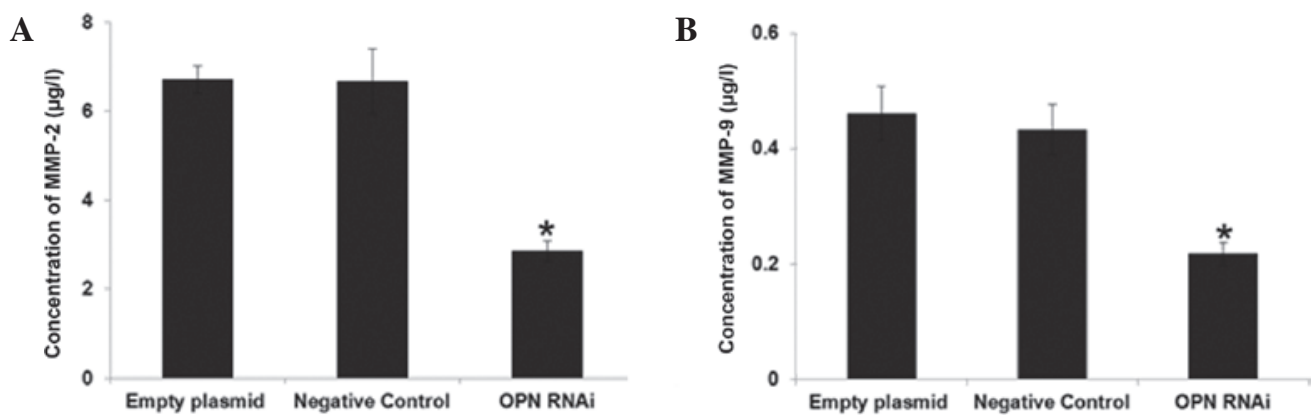

Figure 5. Effect of OPN RNAi on the expression levels of (A) MMP-2 and (B) MMP-9. The concentrations of MMP-2 and MMP-9 in the cell culture medium were analyzed by ELISA. "P<0.05, vs. negative control group. OPN, osteopontin; RNAi, RNA interference; MMP, matrix metalloproteinase. 
to be satisfactory in a number of tumors through RNAi technology (8). Previous studies have demonstrated that inhibition of OPN receptor expression through RNAi significantly inhibited adhesion, migration and distant metastasis of human breast cancer cells $(22,23)$. Gao et al (24) investigated OPN function through the 4T1 and 4T07 mice mammary gland epithelial cell lines. The authors identified that OPN was expressed in the 4T1 cells, resulting in tumorigenesis, while the tumors presented distant metastasis. However, tumors were unable to transfer in $4 \mathrm{~T} 07$ cells that did not express OPN. Similar results have been observed in CT26 colon cancer cells (25). Furthermore, a previous study has demonstrated that the OPN gene is highly expressed in bladder cancer (26). Based on previous studies, OPN-targeting gene therapy was hypothesized to be a potentially novel treatment method for bladder cancer.

In the present study, OPN RNAi was successfully performed. An effective target was successfully selected and transfected with lentivirus, while the efficiency of lentiviral infection in T24 cells was determined. The lentivirus-mediated RNAi of OPN gene was investigated in T24 cells using MTT, flow cytometric and Transwell assays. Five days after transfecting the T24 cells, the mRNA expression of OPN was found to be significantly reduced $(\mathrm{P}<0.05)$ in the interference group compared with the untreated groups. In addition, six days post-transfection, the protein expression of OPN was found to be significantly reduced $(\mathrm{P}<0.05)$ in the interference group compared with the untreated groups. MTT assay revealed that the proliferation of T24 cells decreased due to RNAi. Furthermore, cell cycle analysis demonstrated that cell cycle arrest of T24 cells occurred at $G_{1} / S$ phase upon OPN gene inhibition. Apoptotic analysis revealed that OPN gene interference in T24 cells resulted in the loss of the anti-apoptotic effect of the gene.

OPN plays an important role in cell migration and invasion processes. In addition, a number of studies have demonstrated that OPN promoted tumor invasion and metastasis and regulated MMP-9 secretion (27-31). OPN was shown to combine with integrin $\alpha v \beta 3$ and activate $\mathrm{NF}-\kappa \mathrm{B}$ (nuclear factor- $\kappa \mathrm{B})$ through the PI3K/Akt/IKK $(\kappa \mathrm{B}$ kinase inhibitor) signaling pathway, increasing the secretion of urokinase-type plasminogen activator A (uPA) and promoting tumor invasion $(32,33)$. In the current study, the results demonstrated that OPN gene interference inhibited cell invasion and migration through regulation of the expression levels of MMPs in T24 cells.

In conclusion, the present study verified that recombinant lentiviral vectors carrying the OPN-RNAi sequence can significantly inhibit the proliferation of T24 bladder cancer cells in vitro. RNAi was found to induce apoptosis in T24 cells and reduce invasion in vitro. Therefore, OPN may be a potentially novel target for bladder cancer gene therapy. However, in vitro studies present certain limitations, such as poor targets, safety of the carrier and drug delivery. Therefore, further studies are required prior to the application of the present study in the clinical treatment of bladder cancer. With the development of tumor molecular biology and associated disciplines, as well as the identification of safe and effective vectors, RNAi technology may play an important role in the treatment of bladder cancer.

\section{Acknowledgements}

This study was supported by a grant from the Natural Science Foundation of Luohe Medical College, P.R China (no. 2013-DF-002).

\section{References}

1. Baffa R, Letko J, McClung C, LeNoir J, Vecchione A and Gomella LG: Molecular genetics ddof bladder cancer: targets for diagnosis and therapy. J Exp Clin Cancer Res 25: 145-160, 2006.

2. Stein JP, Lieskovsky G, Cote R, Groshen S, Feng AC, Boyd S, Skinner E, Bochner B, Thangathurai D, Mikhail M, Raghavan D and Skinner DG: Radical cystectomy in the treatment of invasive bladder cancer: long-term results in 1,054 patients. J Clin Oncol 19: 666-675, 2001.

3. Kirkali Z, Chan T, Manoharan M, Algaba F, Busch C, Cheng L, Kiemeney L, Kriegmair M, Montironi R, Murphy WM, Sesterhenn IA, Tachibana $M$ and Weider J: Bladder cancer: epidemiology, staging and grading, and diagnosis. Urology 66 (6 Suppl 1): 4-34, 2005.

4. Hass HG, Nehls O, Jobst J, Frilling A, Vogel U and Kaiser S: Identification of osteopontin as the most consistently over-expressed gene in intrahepatic cholangiocarcinoma: detection by oligonucleotide microarray and real-time PCR analysis. World J Gastroenterol 14: 2501-2510, 2008.

5. Rangaswami H, Bulbule A and Kundu GC: Osteopontin: role in cell signaling and cancer progression. Trends Cell Biol 16: 79-87, 2006.

6. Castellano G, Malaponte G, Mazzarino MC, Figini M, Marchese F, Gangemi P, Travali S, Stivala F, Canevari S and Libra M: Activation of the osteopontin/matrix metalloproteinase-9 pathway correlates with prostate cancer progression. Clin Cancer Res 14: 7470-7480, 2008.

7. Das R, Mahabeleshwar GH and Kundu GC: Osteopontin induces AP-1-mediated secretion of urokinase-type plasminogen activator through c-Src-dependent epidermal growth factor receptor transactivation in breast cancer cells. J Biol Chem 279: 11051-11064, 2004.

8. Sun BS, You J, Li Y, Zhang ZF and Wang CL: Osteopontin knockdown suppresses non-small cell lung cancer cell invasion and metastasis. Chin Med J (Engl) 126: 1683-1688, 2013.

9. Yang L, Zhao W, Zuo WS, Wei L, Song XR, Wang XW, Zheng G and Zheng MZ: Silencing of osteopontin promotes the radiosensitivity of breast cancer cells by reducing the expression of hypoxia inducible factor 1 and vascular endothelial growth factor. Chin Med J (Engl) 125: 293-299, 2012.

10. Tuck AB, Chambers AF and Allan AL: Osteopontin overexpression in breast cancer: knowledge gained and possible implications for clinical management. J Cell Biochem 102: 859-868, 2007.

11. Boldrini L, Donati V, Dell'Omodarme M, Prati MC, Faviana P, Camacci T, Lucchi M, Mussi A, Santoro M, Basolo F and Fontanini G: Prognostic significance of osteopontin expression in early-stage non-small-cell lung cancer. $\mathrm{Br} \mathrm{J}$ Cancer 93: 453-457, 2005

12. Pan HW, Ou YH, Peng SY, Liu SH, Lai PL, Lee PH, Sheu JC, Chen CL and Hsu HC: Overexpression of osteopontin is associated with intrahepatic metastasis, early recurrence, and poorer prognosis of surgically resected hepatocellular carcinoma. Cancer 98: 119-127, 2003.

13. Schorge JO, Drake RD, Lee H, Skates SJ, Rajanbabu R, Miller DS, Kim JH, Cramer DW, Berkowitz RS and Mok SC: Osteopontin as an adjunct to CA125 in detecting recurrent ovarian cancer. Clin Cancer Res 10: 3474-3478, 2004.

14. Mack PC, Redman MW, Chansky K, Williamson SK, Farneth NC, Lara PN Jr, Franklin WA, Le QT, Crowley JJ, Gandara DR and SWOG: Lower osteopontin plasma levels are associated with superior outcomes in advanced non-small-cell lung cancer patients receiving platinum-based chemotherapy: SWOG Study S0003. J Clin Oncol 26: 4771-4776, 2008.

15. Hartung F and Weber GF: RNA blood levels of osteopontin splice variants are cancer markers. Springerplus 2: 110, 2013

16. Dubreuil G, Magliano M, Dubrana MP, Lozano J, Lecomte P, Favery B, Abad P and Rosso MN: Tobacco rattle virus mediates gene silencing in a plant parasitic root-knot nematode. J Exp Bot 60: 4041-4050, 2009. 
17. Stein P, Svoboda P and Schultz RM: RNAi-based methods for gene silencing in mouse oocytes. Methods Mol Biol 957: 135-151, 2013.

18. Meister $\mathrm{G}$ and Tuschl T: Mechanisms of gene silencing by double-stranded RNA. Nature 431: 343-349, 2004.

19. Salido-Guadarrama I, Romero-Cordoba S, Peralta-Zaragoza O, Hidalgo-Miranda A and Rodríguez- Dorantes M: MicroRNAs transported by exosomes in body fluids as mediators of intercellular communication in cancer. Onco Targets Ther 7: 1327-1338, 2014

20. Livak KJ and Schmittgen TD: Analysis of relative gene expression data using real-time quantitative PCR and the 2 (-Delta Delta C (T)) Method. Methods 25: 402-408, 2001.

21. ES Sørensen, P Højrup and TE Petersen: Posttranslational modifications of bovine osteopontin: identification of twenty-eight phosphorylation and three O-glycosylation sites. Protein Sci 4: 2040-2049, 1995.

22. MiZ, Guo H and Kuo PC: Identification of osteopontin-dependent signaling pathways in a mouse model of human breast cancer. BMC Res Notes 2: 119, 2009.

23. Shevde LA, Samant RS, Paik JC, Metge BJ, Chambers AF, Casey G, Frost AR and Welch DR: Osteopontin knockdown suppresses tumorigenicity of human metastatic breast carcinoma, MDA-MB-435. Clin Exp Metastasis 23: 123-133, 2006.

24. Gao C, Mi Z, Guo H and Kuo PC: Osteopontin regulates ubiquitin-dependent degradation of Stat1 in murine mammary epithelial tumor cells. Neoplasia 9: 699-706, 2007.

25. Wai PY, Mi Z, Guo H, Sarraf-Yazdi S, Gao C, Wei J, Marroquin CE, Clary B and Kuo PC: Osteopontin silencing by small interfering RNA suppresses in vitro and in vivo CT26 murine colon adenocarcinoma metastasis. Carcinogenesis 26: 741-751, 2005.
26. Zaravinos A, Lambrou GI, Volanis D, Delakas D and Spandidos DA: Spotlight on differentially expressed genes in urinary bladder cancer. PLoS One 6: e18255, 2011.

27. Rangaswami H, Bulbule A and Kundu GC: Osteopontin: role in cell signaling and cancer progression. Trends Cell Biol 16: 79-87, 2006.

28. Castellano G, Malaponte G, Mazzarino MC, Figini M, Marchese F, Gangemi P, Travali S, Stivala F, Canevari S and Libra M: Activation of the osteopontin/matrix metalloproteinase-9 pathway correlates with prostate cancer progression. Clin Cancer Res 14: 7470-7480, 2008.

29. Likui W, Hong W, Shuwen Z, Yuangang Y and Yan W: The potential of osteopontin as a therapeutic target for human colorectal cancer. J Gastrointest Surg 15: 652-659, 2011.

30. Anborgh PH, Mutrie JC, Tuck AB and Chambers AF: Pre- and post-translational regulation of osteopontin in cancer. J Cell Commun Signal 5: 111-122, 2011.

31. Ramchandani D and Weber GF: An osteopontin promoter polymorphism is associated with aggressiveness in breast cancer. Oncol Rep 30: 1860-1868, 2013.

32. Rangaswami H, Bulbule A and Kundu GC: Nuclear factor-inducing kinase plays a crucial role in osteopontin-induced MAPK/IkappaBalpha kinase-dependent nuclear factor kappaB-mediated promatrix metalloproteinase-9 activation. J Biol Chem 279: 38921-38935, 2004.

33. Tang X, Li J, Yu B, Su L, Yu Y, Yan M, Liu B and Zhu Z: Osteopontin splice variants differentially exert clinicopathological features and biological functions in gastric cancer. Int J Biol Sci 9: 55-66, 2013. 